\title{
Modeling of Ship Micro-Grid Based on Wind and Solar Power Generation Technology
}

\author{
Lanyong Zhang ${ }^{\mathrm{a}, 1}$ and Ziming Yuan ${ }^{\mathrm{a}}$ \\ ${ }^{a}$ College of Intelligent Science and Engineering ,Harbin Engineering University, \\ Harbin 150000, China
}

\begin{abstract}
Under the influence of environmental issues and energy crises, wind and solar power generation technologies have developed rapidly. Compared with terrestrial micro-grid, this technology has relatively few applications on ships. Aiming at the problems of low energy utilization rate of ship micro-grid, imperfect control strategy, and single simulation situation, this paper uses the construction method of terrestrial micro-grid to build a detailed ship micro-grid model based on wind and solar power generation technology on the MATLAB/simulink simulation platform, and uses hill climbing search Method and disturbance observation method to control wind and photovoltaic power generation system. In the simulation process, several situations of wind speed, light intensity, and load sudden changes during the operation of the micro-grid were simulated. The simulation results show that the micro-grid model can track the maximum power point in real time, and the wind energy utilization rate is increased to 0.48 , and the bus voltage and current are equal. The actual operation requirements are met, and the correctness and effectiveness of the simulation model and control strategy are verified, which is helpful to the indepth study of the construction of the ship micro-grid model.
\end{abstract}

Keywords. Maximum power tracking, ship microgrid, solar power, wind power

\section{Introduction}

With the continuous development of the marine economy, the number of inland rivers and marine vessels has continued to increase, and the prevention and control of shipping pollution from ships has become a focal issue. The International Maritime Organization (IMO) pointed out in a relevant survey in 2018 that the global carbon emissions from ships accounted for $3.3 \%$ of the year. If it cannot be controlled in time, it is expected that its share will increase to $18 \%$ in 2050 . Therefore, as the main carrier of marine transportation, in order to save fuel costs, reduce fossil energy consumption and carbon emissions, the development and utilization of new energy is of great significance of the development of future ship power[1].

At present, the application of clean energy as wind and solar power generation technology on board the ship by researchers more and more attention. Reference [2] used PSCAD/EMTDC simulation environment to establish simulation models on wind power

${ }^{1}$ Corresponding author, Lanyong Zhang, College of Intelligent Science and Engineering, Harbin Engineering University, Harbin 150000,China; Email: zlyalf@sina.com. 
generation, photovoltaic systems, and energy storage systems based on the operating characteristics of the micro-grid, and studies how the micro-grid can be made normal through a control strategy under changes in wind speed and light intensity run. Reference [3] designed a marine micro-grid monitoring system and PLC control program based on wind-solar complementary technology with reference to the terrestrial micro-grid system, which improved the reliability of the ship's micro-grid operation and monitoring. Reference [4] established a single-phase micro-grid system modeled based on the DC bus, using this model and control strategy to simulate the transition state and power flowed direction during micro-grid mode switching, verifying the feasibility and effectiveness of the model. Reference [5] built a machine-side system simulation modeled based on dual closed-loop PI controlled. Through simulation and analysis, it is proved that the dual closed-loop PI control strategy is feasible to achieve maximum power tracking down different wind speeds, and the wind energy utilization rated reaches 0.438. Reference [6] used MATLAB/Simulink software to build a photovoltaic cell model, a simplified fuel cell model, and a diesel generator model and other micro power models for simulation analysis. The model can better simulated the actual operating conditions.

Most of the above-mentioned documents adopt simplified models without realizing maximum power tracking, and the control strategy is not perfect, the energy utilization rate is not high enough, and the simulation situation is relatively simple. Aiming at these problems, first analyze and derive the mathematical model of each power generation unit, and then in the MATLAB / Simulink in detail the establishment of a wind photovoltaic systems and grid-side simulation models, and design appropriate control strategies to achieve maximum power tracking, Constructed a complete simulation model. Based on this, a simulation study was carried out on the situation of wind speed, light intensity and loads changes. The simulation results showed the correctness of the built micro-grid simulation model and the effectiveness of the control strategy.

\section{Wind turbine model and control}

\subsection{Mathematical model of wind power generation}

- Mathematical model of wind turbine

Permanent magnet direct-drive wind turbine. The basic principle is to convert wind energy into mechanical rotational energy, the core member is a wind turbine, when the wind blowing blades driven at a constant speed wind turbine rotates, the air moving energy conversion. The mechanical energy for the rotation of the wind wheel drives the permanent magnet generator to emit current. The process of converting wind energy into wind turbine power output is a complex aerodynamic process. The mechanical power captured by wind turbines $P_{m}$ can be expressed as[7] :

$$
P_{m}=\frac{1}{2} \rho S V_{0}^{3} C_{p}(\beta, \lambda)
$$

Where, $\rho$ is the air density; $S$ is the area of the sweeping wind wheel; $V_{0}$ is the input wind speed; $C_{p}(\beta, \lambda)$ is the wind energy utilization coefficient; $\lambda$ is the tip speed ratio; $\beta$ is the blade pitch angle number. In the case of a given wind speed, the wind power captured by the wind turbine mainly depends on the wind energy utilization coefficient $C_{p}(\beta, \lambda)$. According to the research of Heier et al., the classic $C_{p}$ calculation formula is: 


$$
\begin{aligned}
& C_{p}(\beta, \lambda)=0.5176\left(\frac{116}{\lambda^{*}}-0.4 \beta-5\right) e^{-\frac{21}{\lambda^{*}}}+0.0068 \lambda \\
& \frac{1}{\lambda^{*}}=\frac{1}{\lambda+0.08 \beta}-\frac{0.035}{\beta^{3}+1} ; \lambda=\frac{\omega_{T} R}{V_{0}}
\end{aligned}
$$

According to Betz theory, $\mathrm{C}_{\mathrm{p}}$ the theoretical maximum value is 0.593 , that is, the maximum kinetic energy obtained by the wind wheel in an ideal state accounts for $59.3 \%$ of the air kinetic energy on the wind wheel area, and the maximum value of the wind energy utilization coefficient of the actual three-blade wind turbine can reach 0.48 about. According to different $\beta, \lambda$ values, the $C_{p}(\beta, \lambda)$ curve calculated by the formula is shown in Fig.1.

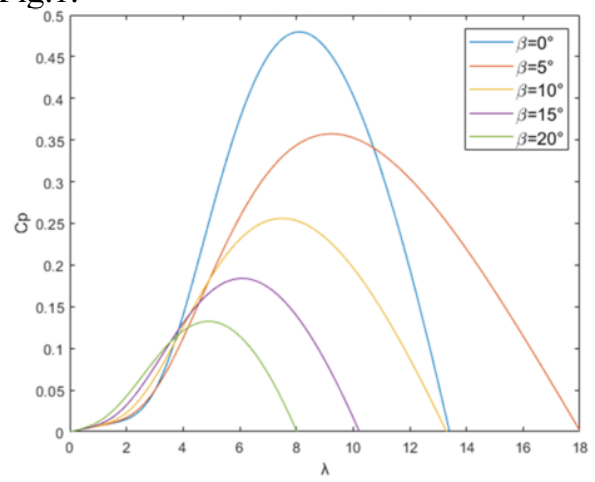

Figure 1. Wind energy utilization curve

- $\quad$ Mathematical model of Permanent Magnet Synchronous Generator(PMSG) Permanent magnet synchronous generator after coordinate transformation, the timevarying inductance can be eliminated, and a mathematical model of the synchronous generator with clear physical meaning can be obtained.

1) The stator voltage equation is:

$$
\left\{\begin{array}{l}
u_{s d}=R_{s} i_{s d}+L_{d} \dot{l}_{s d}-\omega_{r} L_{q} i_{s q} \\
u_{s q}=R_{s} i_{s q}+L_{d} \dot{l_{s q}}+\omega_{r} L_{d} i_{s d}+\omega_{r} \Psi_{r}
\end{array}\right.
$$

Where, $\mathrm{u}_{\mathrm{sd}}, \mathrm{u}_{\mathrm{sq}}, \mathrm{i}_{\mathrm{sd}}, \mathrm{i}_{\mathrm{sq}}, \Psi_{\mathrm{r}}$ respectively the generator stator voltage, current, and rotor permanent magnet flux linkage, $R_{s}$ is torque; $\omega_{r}$ is the generator rotational speed; $\mathrm{L}_{\mathrm{q}}$ and $\mathrm{L}_{\mathrm{d}}$ the generator dq-axis inductance.

2) Torque and motion equation are:

$$
\left\{\begin{array}{l}
T_{e}=\frac{3}{2} n_{p} i_{s q}\left(\left(L_{q}-L_{d}\right) i_{s d}+\Psi_{r}\right) \\
T_{e}-T_{m}=\frac{J}{N_{p}} \frac{d \omega_{T}}{d t}
\end{array}\right.
$$

Where, $\mathrm{T}_{\mathrm{e}}$ is the electromagnetic torque; $\mathrm{T}_{\mathrm{m}}$ is the mechanical torque; Jis the moment of inertia of the generator rotor; $\mathrm{N}_{\mathrm{p}}$ is the number of pole pairs; $\omega_{\mathrm{T}}$ is the blade speed. The above two sets of equations constitute a complete mathematical model of PMSG.

\subsection{Wind power generation control strategy}

- Maximum power point tracking control 
It can be seen from Fig. 1 that when the pitch angle $\beta$ is fixed, $C_{p}$ is only related to $\lambda$, and there is only one $C_{p}$ that maximizes $\lambda$, which is called the best tip speed ratio $\lambda_{\text {opt }}$, At this time, the corresponding optimal speed is $\omega_{\text {opt }}$, and the corresponding wind energy utilization coefficient is recorded as $C_{\text {pmax }}$. Therefore, $\omega_{T}$ should be changed with the change of wind speed to ensure that the tip speed ratio is always the best tip speed ratio. Therefore, the maximum power tracking control of wind turbines means that under different input wind speeds, by controlling the speed of the wind turbine, $C_{p}$ is always kept at the maximum value.

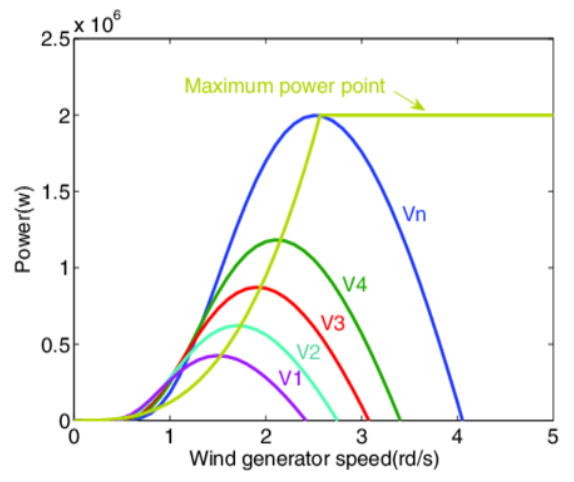

Figure 2. maximum power-optima speed curve

Fig. 2 is the curve of the maximum power and the optimal speed of the wind turbine under different wind speeds. Connecting the vertices of the curves in Fig.2 can get an optimal power and speed curve, as shown by the thick green solid line in the figure. Each maximum power point $\mathrm{P}_{\max }$ on the curve corresponds to an optimal rotation speed $\omega_{\mathrm{opt}}$ under the current wind speed.

- $\quad$ Principle of MPPT based on hill climbing search method

Compared with the best blade tip speed ratio method and the power signal feedback method, the hill-climbing search method[8] does not required any device for measuring wind speed and does not need to know the exact power characteristics of the wind turbine. The requirements for the power characteristics of wind turbines are relatively low, and the control process is basically realized by software programming; it is independent of the design parameters of the wind turbine and can track the maximum power point autonomously. Impose rotation speed disturbance to cause a change in output power. If the change is greater than zero, when the system becomes stable, continue to add the same sign as the previous disturbance, until the output power change starts to be less than zero before changing the next time The sign of the disturbance. Through the process of gradual optimization, the operating point of the wind turbine will approach the maximum power point. However, the time constant of this method is relatively large, and it takes a long time to realize the maximum power tracking.

\section{Photovoltaic power generation system model and control}

\subsection{Mathematical model of photovoltaic power generation}

The equivalent circuit diagram of the photovoltaic cell is shown in Fig.3. 


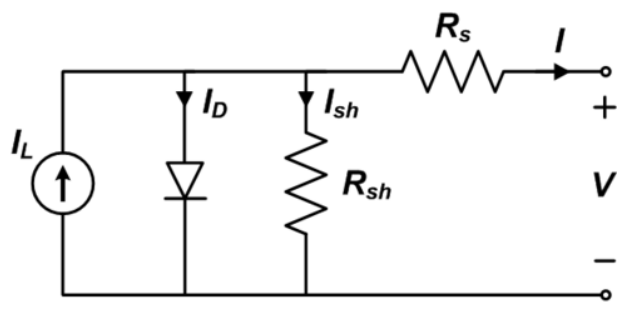

Figure 3. Photovoltaic cell equivalent circuit

The constant current source $I_{L}$ in the figure can be regarded as a constant current source that generates current in a photovoltaic cell, and in parallel with it is a forwardbiased diode. The leakage current through the diode is denoted as $I_{D}$, which is called dark current; in practical applications, it can be considered that the parallel resistance $R_{s h}=$ $\infty$; the value of the series equivalent resistance $R_{S}$ is generally between $7.7 \sim 15.3 \mathrm{~m} \Omega$, which can be ignored in the calculation; the output voltage $V$ is and the output current $I$ is affected by changes in the ambient temperature and photovoltaic intensity Influence, equations[9] (5) (10) represent the $I-V$ characteristic equation.

$$
\begin{aligned}
I & =I_{S C}\left(1-A\left(\frac{U-D}{e^{B U_{o c}}}-1\right)\right)+C \\
A & =\left(1-\frac{I_{m}}{I_{S C}}\right) e^{-\frac{U_{m}}{B U_{o c}}} \\
B & =\frac{\frac{U_{m}}{U_{o c}}-1}{\ln \left(1-\frac{I_{m}}{I_{S C}}\right)} \\
C & =\frac{\alpha R}{R_{r e f}} E+\left(\frac{R}{R_{r e f}}-1\right) I_{S C} \\
D & =-\beta E-R_{S} C \\
E & =T_{m}-T_{r e f}
\end{aligned}
$$

Where, $\alpha, \beta$ respectively the reference radiation current and voltage temperature coefficient; $I_{S C} \approx I_{L}$ is the short-circuit current; $U_{O C}$ is the open circuit voltage; $U$ is the corresponding photovoltaic array voltage; $R_{r e f}$ is the reference radiation intensity, $1 \mathrm{kw} / \mathrm{m}^{2} ; T_{\text {ref }}$ is the reference ambient temperature $25^{\circ} \mathrm{C} ; I_{m}, U_{m}$ is the current and voltage at the corresponding maximum power point.

The output power of the photovoltaic array is:

$$
P=I U=\left(I_{S C}\left(1-A\left(\frac{U-D}{e^{B U_{o C}}}-1\right)\right)+C\right) U
$$

According to formulas (5) (11), $I-U$ characteristic curve and $P-U$ characteristic curve under any ambient temperature and light radiation can be obtained, as shown in Fig.4 and Fig.5. 


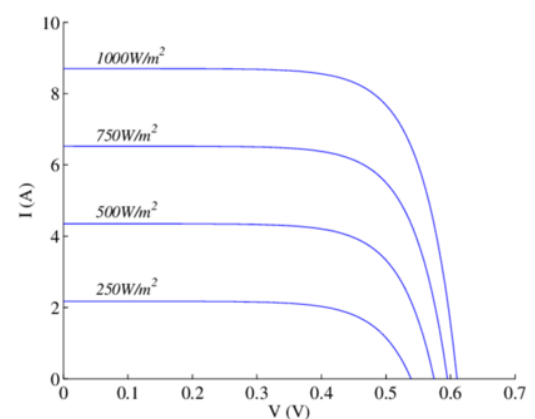

Figure 4. I-V characteristic curve

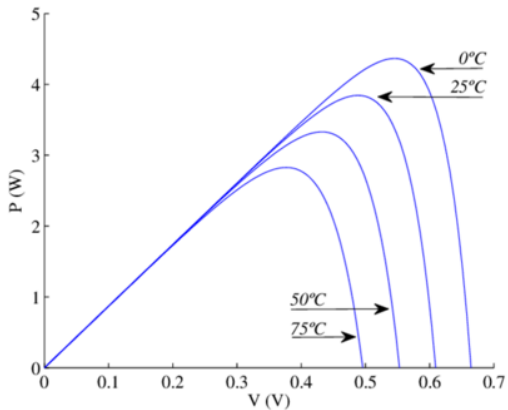

Figure 5. P-V characteristic curve

\subsection{Photovoltaic power generation control strategy}

It can be seen from the output power curve of the photovoltaic cell in Fig. 5 that when the temperature is constant, There is a unique $U_{m}$ that makes $P$ reach the maximum power point. Therefore, the maximum power output can be controlled by controlling the output voltage $U_{m}$ of the photovoltaic cell, the principle is to detect the maximum power point of the photovoltaic array under different light intensity and ambient temperature, compare and optimize through the MPPT algorithm, and determine the working voltage corresponding to the maximum power point under this working condition, so that the photovoltaic array is intelligent under different working conditions Maximum output power.

Due to the simple structure of the disturbance observation method[10], there are fewer parameters to be measured, and it is easy to implement in the system, so this paper adopts the disturbance observation method as the photovoltaic array MPPT control strategy. Its algorithm flow chart is shown as in Fig.6

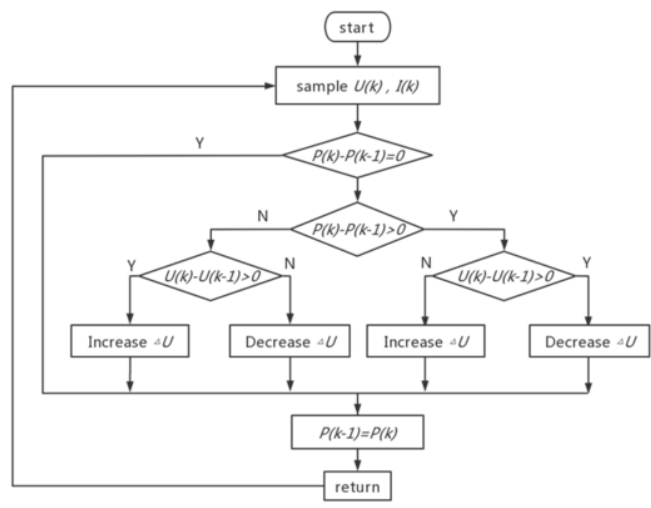

Figure 6. Process of disturbance observation method

The specific method is: First change the output voltage $\Delta U$ of a certain amount of photovoltaic cells, and then implement sampling the output voltage $U(k)$ and current $I(k)$ of the photovoltaic cells, calculate the output power $P(k)$ and compare it with the previous output power $P(k-1)$; if it is less than $P(k-1)$, it means this time This variable of voltage makes the output power decrease, then the control direction needs to be changed; if it is greater than $P(k-1)$, the original increase or decrease direction is 
maintained, so that the output power can be changed in the direction of increase in the constant repeated disturbance, observation and In comparison, the photovoltaic cell can reach the maximum power point and achieve the maximum power output.

\section{Simulation verification}

\subsection{Partial simulation analysis of wind power generation}

As shown in Fig.7, according to the mathematical models and wind turbine control strategies shown, a wind power generation system simulation model based on the hillclimbing search method to achieve maximum power point tracking is built in Simulink. The wind power generation part is composed of wind speed transmission module, PMSG, rectifier and MPPT module. The wind speed drive simulates the input wind speed, realizes the maximum wind machinery power tracking through the MPPT module based on the hill climbing search method, feeds back the speed to the generator, outputs the load torque to drive the generator, and the output power controls the generator DC side rectifier to realize the generator speed control.

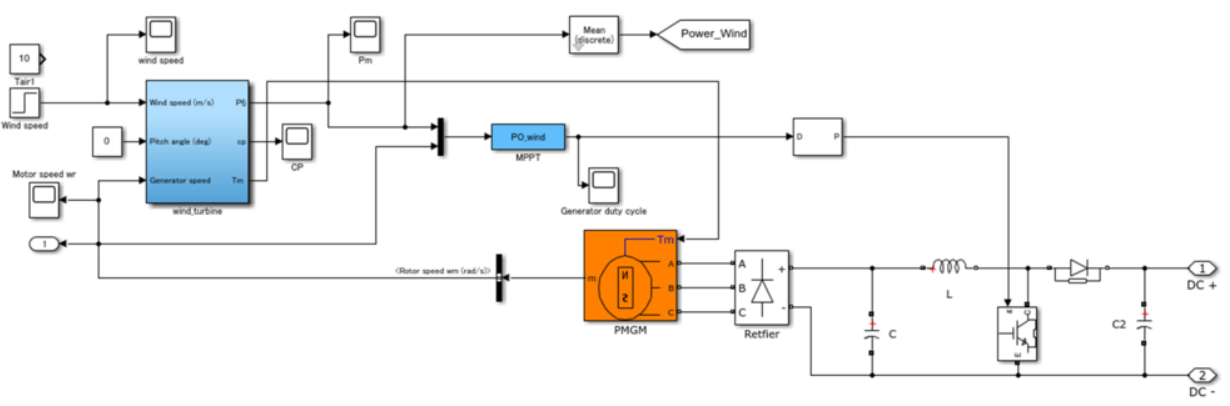

Figure 7. Wind power generation part

In the simulation process, the simulation time is set to 4 seconds, the initial wind speed is set to $8 \mathrm{~m} / \mathrm{s}$, and the wind speed changes from $8 \mathrm{~m} / \mathrm{s}$ to $12 \mathrm{~m} / \mathrm{s}$ at $1 \mathrm{~s}$. Fig. 8 shows the simulation results of wind output power. It can be seen from the figure that when the simulated wind turbine is just started, the power will fluctuate in a small range due to unstable wind speed, but it is still within the controllable range. When the wind speed changes suddenly, the output power is quickly changed and the output power is kept stable at $18 \mathrm{~kW}$. Fig.9 is a graph of the simulation results of the wind energy utilization coefficient curve. It can be seen that the maximum wind energy utilization coefficient can reach about 0.48 , with rapid dynamic response and stable maintenance.

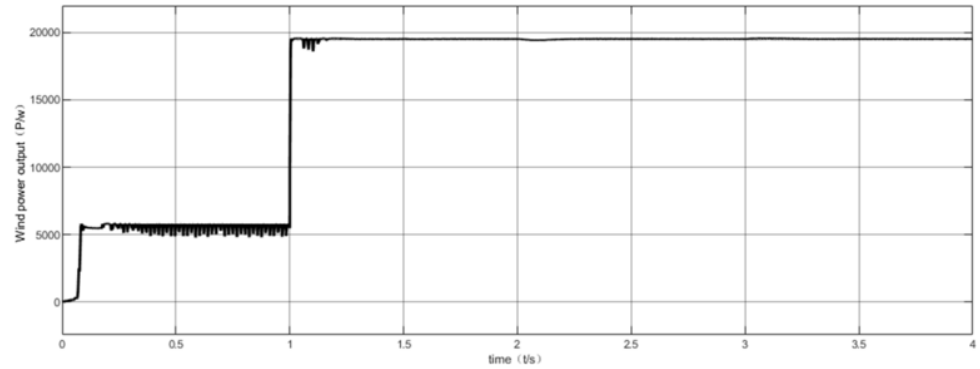

Figure 8. Wind power output 


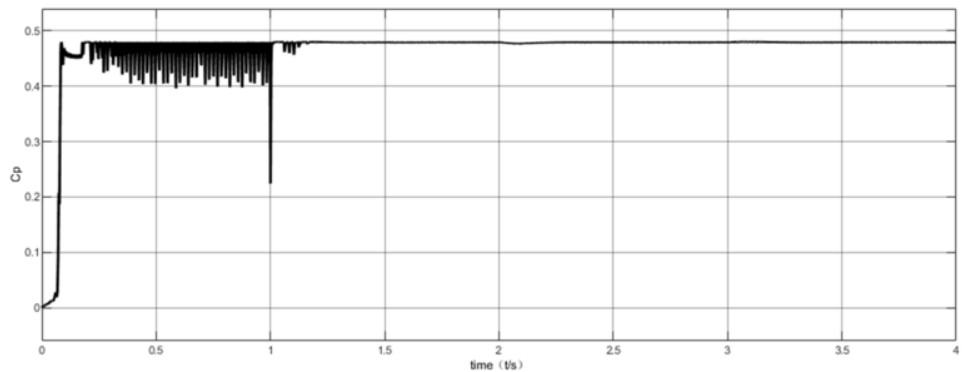

Figure 9. Wind energy utilization coefficient curve

\subsection{Partial simulation analysis of photovoltaic power generation}

As shown in Fig.10, based on the mathematical model and photovoltaic power generation control strategy shown, a photovoltaic power generation system simulation model based on the disturbance observation method to achieve maximum power point tracking is built. The photovoltaic power generation part mainly consists of photovoltaic cell modules, MPPT modules, voltage stabilizing and filtering circuits. The input variable $\mathrm{S}$ is the solar radiation intensity, $\mathrm{T}$ is the ambient temperature, and the maximum power is tracked in real time through the MPPT module based on the disturbance observation method.

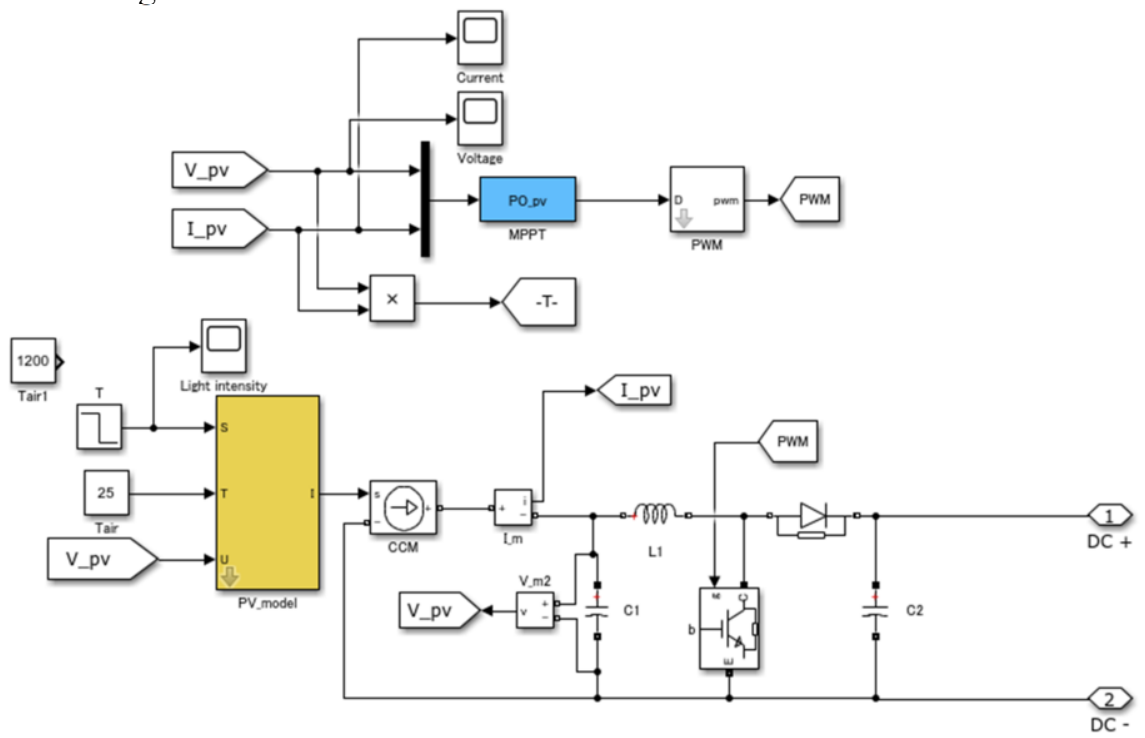

Figure 10. Photovoltaic power generation part

Set the simulation time to 4 seconds, the ambient temperature to $25^{\circ} \mathrm{C}$, the initial light radiation intensity is set to $1200 \mathrm{~W} / \mathrm{m}^{2}$, and the sudden change to $1000 \mathrm{~W} / \mathrm{m}^{2}$ at $1.5 \mathrm{~s}$. Fig. 11 shows the simulation results of the photovoltaic output power. Due to the light radiation intensity The power dropped from $3.76 \mathrm{~kW}$ to $3 \mathrm{~kW}$ at $1.5 \mathrm{~s}$, and the output power quickly returned to stability. 


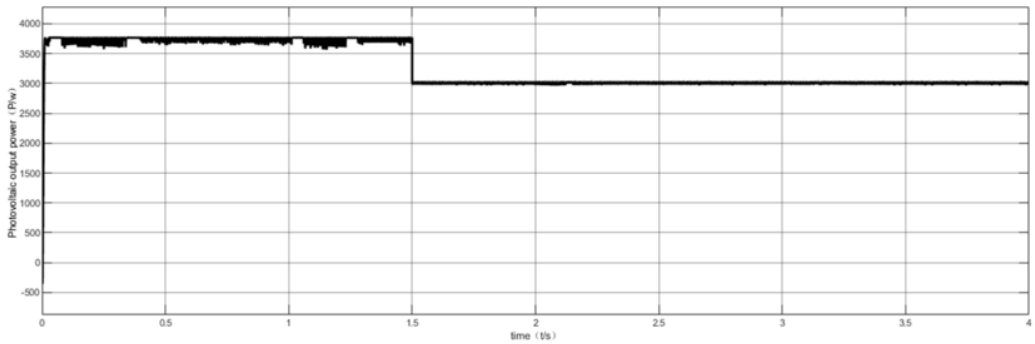

Figure 11. Photovoltaic output power

\subsection{Simulation analysis on the grid-connected side}

As shown in Fig.12, the grid-connected side simulation model is built, which is composed of inverter modules, power measurement circuits and load cells. The inverter adopts double-loop cascade control with current, which can effectively stabilize the bus voltage and realize the stable operation of the system. The simulation sets the initial load power to $5 \mathrm{~kW}$. At $2 \mathrm{~s}$, the load power changes from $5 \mathrm{~kW}$ to $8 \mathrm{~kW}$, and then changes back to $5 \mathrm{~kW}$ at $3 \mathrm{~s}$. The bus voltage, current and power fluctuations are detected.

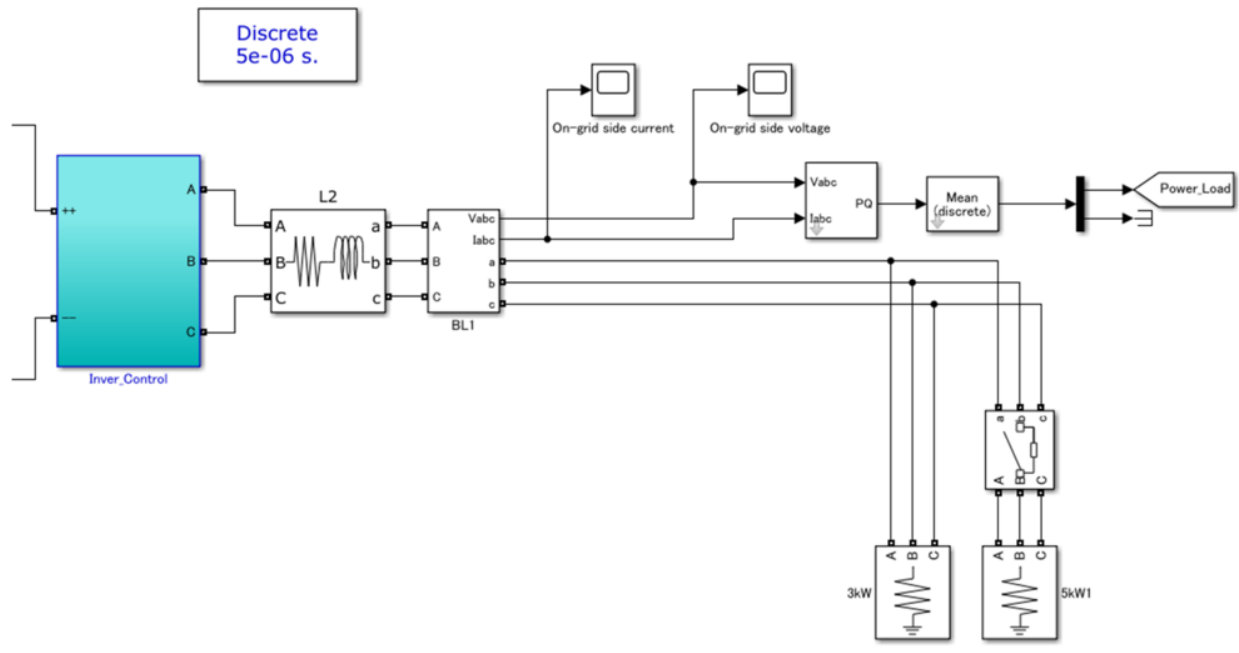

Figure 12. Grid-connected side simulation model.

The simulation result is shown in Fig.13. It can be seen from the figure that the output voltage and current are all standard sinusoidal waveform. At the same time, the line responds quickly, and the voltage and current can quickly return to a stable state. Both can quickly and effectively keep the bus voltage and current stable, and well meet the actual grid connection requirements, and further verify the correctness and effectiveness of the simulation model. 

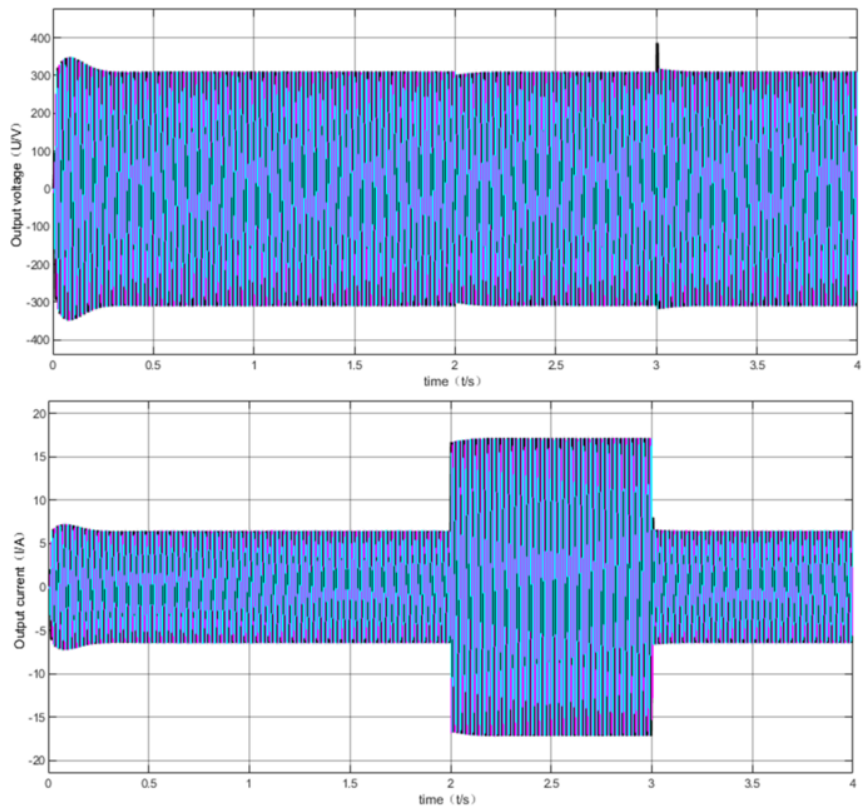

Figure 13. Output voltage and current

\section{Conclusion}

With the country's deep emphasis on environmental protection and the continuous maturity of micro-grid technology, This paper builds a detailed micro-grid simulation model in MATLAB/Simulink based on the mathematical model of wind turbines and photovoltaic arrays, The wind power and photovoltaic power generation parts of the model adopt the MPPT control strategy of the hill climbing search method and the disturbance observation method respectively, and are verified by simulation, Under the changes of wind speed and light intensity, the maximum power point can be tracked in real time, and the wind energy utilization rate can reach 0.48 , and when the load is added and cut off on the grid-connected side, the model can efficiently and quickly restore and maintain the stability of the bus voltage and current, which fully meets the operation of the power grid. It shows that the simulation model built in this paper is correct and the control strategy is effective, There are still some problems and deficiencies in this research, but which has certain reference value for improving and perfecting the modeling and simulation of the new energy ship micro-grid.

\section{References}

[1] Wang Chengshan, "Micro analysis and simulation of grid theory," Beijing: Science Press, 2013, pp.162.

[2] Han Zhou and Ren Yongfeng, "Micro-grid modeling and simulation based on distributed power sources," Computer Simulation, 2014, 31(5), pp. 120-124.

[3] Yan Juhuai, Tan Yinchao, "Design of ship micro-grid monitoring system based on wind-solar complementary technology," China Water Transport, 2018,18(03), pp.80-82. 
[4] Guo Tianyong, Zhao Gengshen, Zhao Yao, "Modeling and simulation of microgrid system based on wind-solar complementation," Power System Protection and Control, 2010, 38(21), pp. 104-108.

[5] Lin Li, He Yang, Zhou Jianhua, "Modeling and simulation of direct drive permanent magnet synchronous wind turbine side system," Electric Drive, 2020, 50(02), pp. 73-76.

[6] Wang Ling, Li Peiqiang,Li Xinran, "Micro power supply modeling and its application in micro grid simulation," Journal of Electric Power System and Automation, 2010, 22(3), pp. 32-38.

[7] S. Kumari, V. Kushwaha and TN Gupta, "A Maximum Power Point Tracking For a PMSG Based Variable Speed Wind Energy Conversion System," 2018 International Conference on Power Energy, Environment and Intelligent Control(PEEIC), 2018, pp. 789-794.

[8] Kong Zhendong, Hong Chengcheng, “Grid-connected permanent magnet synchronous wind power generation system and maximum wind energy tracking," New Industrialization, 2019, 9(03), pp. 7-12.

[9] BINAYAK B, SHIVA R P, "Mathematical modeling of hybrid renewable energy system: A review on small hydro-solar-wind power generation," International Journal of Precision Engineering and Manufacturing-Green Technology, 2014(1), pp. 157-173.

[10] Geng Longhai, Li Zhaoxia,Quan Xuezheng, "Photovoltaic cell characteristics and MPPT simulation study of disturbance observation method," Tibet Technology, 2020(10), pp. 13-17. 